\title{
Energy auditing of pearl millet production system in dry land region of Haryana Agrcultural University in Hisar, India
}

\author{
Raveena Kargwal, Yadvika, M. K. Garg, V. K. Singh and Y. K. Yadav
}

Received : 09.05.2019; Revised : 20.08.2019; Accepted : 06.09.2019

See end of the Paper for authors' affiliation

Correspondence to :

Raveena Kargwal

Department of Processing and Food Engineering, College of Agricultural Engineering and Technology, C.C.S. Haryana Agricultural University, Hisar (Haryana) India

Email : raveenakargwal@ gmail.com
-ABSTRACT : Pearl millet, also known as Bajra is one of the major Kharif food crops of arid and semi-arid cropping region of India. It ranks first under the category of millet in India in terms of area, production and productivity. An on-the-farm evaluation of energy inputs and output was calculated to determine the distribution of main energy sources (i.e. human, fuel, machinery, seed and fertilizer) used in pearl millet cultivation. This study was carried out at dryland farm area, C.C.S. Haryana Agricultural University, Hisar, Haryana, India. The results indicated that the total input and output energy use was $4785.52 \mathrm{MJ} \mathrm{ha}^{-1}$ and $29400.00 \mathrm{MJ} \mathrm{ha}^{-1}$, respectively. With 56 per cent, the fertilizer had the highest contribution in the energy input followed by diesel fuel (29\%) and human $(12 \%)$. The input-output ratio was observed to be 6.12 . The share of indirect energy was found to be higher as compared to direct energy sources.

- KEY WORDS : Energy input-output, Energy ratio, Pearl millet, Yield

- HOW TO CITE THIS PAPER : Kargwal, Raveena, Yadvika, Garg, M.K., Singh, V.K. and Yadav, Y.K. (2019). Energy auditing of pearl millet production system in dry land region of Haryana Agrcultural University in Hisar, India. Internat. J. Agric. Engg., 12(2) : 203-207, DOI: 10.15740/ HAS/IJAE/12.2/203-207. Copyright@ 2019: Hind Agri-Horticultural Society. 